\title{
Knowledge, Attitude and Practice of Biomedical Waste Management among Health Care Personnel in a Secondary Care Hospital of Al Buraimi Governorate, Sultanate of Oman
}

\author{
Ahmed Yar Mohammed Dawood Al Balushi ${ }^{1}$, Muhammad Muqeet Ullah ${ }^{1}$, Amal Ali Al Makhamri ${ }^{2}$, \\ Fatma Sulieman Al Alawi ${ }^{2}$, Mansoor Khalid ${ }^{3}$ \& Hilal Masaud Al Ghafri ${ }^{4}$ \\ ${ }^{1}$ Directorate of Communicable Diseases Surveillance and Control, Directorate General of Health Services, Al \\ Buraimi Governorate, Ministry of Health, Oman \\ ${ }^{2}$ Department of Professional Development and Career Guidance, Directorate General of Health Services, Al \\ Buraimi Governorate, Ministry of Health, Oman \\ ${ }^{3}$ Department of Laboratory Services, Al- Buraimi Hospital, Al Buraimi Governorate, Ministry of Health, Oman \\ ${ }^{4}$ Department of Health Information and Statistics, Directorate of Planning and Studies, Directorate General of \\ Health Services, Al Buraimi Governorate, Ministry of Health, Oman \\ Correspondence: Ahmed Yar Mohammed Dawood Al Balushi, Directorate of Communicable Diseases \\ Surveillance and Control, Directorate General of Health Services, Al Buraimi Governorate, Ministry of Health, \\ Sultanate of Oman, P.O. Box: 8, 512 GSM, Oman. Tel: 96-892-361-634. E-mail: baloch2020@hotmail.com
}

Received: December 30, 2017 Accepted: January 23, 2018 Online Published: February 9, 2018

doi:10.5539/gjhs.v10n3p70 URL: https://doi.org/10.5539/gjhs.v10n3p70

\begin{abstract}
Background: Due to existence of highly infectious materials, the biomedical waste can be a probable source for transmission of diseases as well as occupational hazards among health care workers if not adequately managed. Objective: To assess the knowledge, attitude and practices of biomedical waste management among health care personnel in a secondary hospital of Al Buraimi Governorate, Sultanate Oman.
\end{abstract}

Methodology: A Cross sectional descriptive self-administered questionnaire based study was conducted among 207 subjects from $30^{\text {th }}$ September 2015 to $30^{\text {th }}$ March 2016 in Al-Buraimi hospital, Oman. Stratified random sampling comprised of four strata (100 nurses, 65 doctors, 22 housekeeping staff and 20 laboratory technicians).Chi-Square test was applied using SPSS version 21 with significance level $\leq 0.05$. Confidentiality was maintained with ethical approval from research committee and informed formal consent was taken from the participants.

Result: Overall response rate was $125(60.3 \%)$ from total 207, mean age $36.14 \pm 8.9$ and age ranges from 20 to 58 years with mean age (doctors 42.5 , nurses 29.8 , laboratory technician 29.2 and housekeeping staff 36 ). Female proportion of $82(65.6 \%)$ was higher as compare to males $43(34.4 \%)$. The study was analyzed on the basis of "satisfactory" and "unsatisfactory" scores using "cut-off point" tools. Nurses had better satisfactory knowledge (90.9\%), attitude (94.5\%) and practice (80\%) scores as compare to other participants. The overall "satisfactory" knowledge, attitude and practice scores were found to be statistically insignificant $(\mathrm{P}=0.100, \mathrm{P}=0.346, \mathrm{P}=0.364$ respectively). No significant relationship established between dichotomized variables of knowledge and practice $(\mathrm{P}=0.264)$ as well as attitude and practice $(\mathrm{P}=0.147)$.

Conclusion: The "satisfactory" scores of knowledge, attitude and practice were found to be higher among nurses as compared to other participants, which may be due to intensive patient care and more involvement in biomedical waste management as well as greater responsibility allocated by hospital administration.

Keywords: biomedical waste management, health care personnel, knowledge, attitude and practice

\section{Introduction}

Globally, there was a constant increase and expansion in the number of health care institutions and hospitals to meet the health care facilities required of the alarming population expansion (Tesfahun, Kumie, \& Beyene, 2016). An increase and expansion in the number of hospitals and health care facilities, causes an increase in the utilization of disposable medical materials, which further contributed in production of a large amount of biomedical wastes in 
these health care facilities (WHO, 2002; Karamouz, Zahraie, Kerachian, Jaafarzadeh, \& Mahjouri, 2007).

The introduction of more complicated equipments and overall medical advancement causes an increase in waste production per patient in health care facilities globally (Radha, Kalaivan, \& Lavanya, 2009). The increased production rate of biomedical waste was combined by mishandling and poor disposal methods (Hassan, Ahmed, \& Rahman, 2008). The risk of disease transmission was raised among the health care workers and other environmental issues such as pollution (Awad, Obeidat, \& Shareef, 2004). On the basis of these facts, incorporation of an integrated biomedical waste management system for hospitals and health care facilities was becoming a "cross cutting issue" (Nema, Pathak, \& Bajaj, 2011).

In 2011, WHO stated that high developed countries produce an average up to $0.5 \mathrm{KG}$ of hazardous waste per hospital bed per day while the figure for developing countries was only $0.2 \mathrm{KG}$ per hospital bed per day. Biomedical waste was often not properly segregated in to hazardous or non hazardous wastes that made the actual amount of hazardous waste possibly much higher. $85 \%$ of generated waste from hospitals and other health care facilities were in fact non-hazardous while remaining $15 \%$ is considered to be hazardous materials that may be radioactive, toxic or infectious (WHO, 2011).

Like several other countries, Sultanate of Oman was putting great effort to improve its biomedical waste management practices. In this regard, Oman joined the Basel Convention on Controlling Trans-boundary movement of hazardous waste and their disposal in 1995 (The Basel Convention, 1989). The aim of the convention was to stop the spread of the waste business, which involved the transportation of waste from developing and industrial countries to underdeveloped countries for treatment (Tiemann, 1998). Also, several Gulf Cooperation Council (GCC) States singed or agreed on the convention, avoiding the waste transportation across its national boundaries (Al Shallash \& Shereif, 2007).

Similar to other secondary hospitals within Sultanate of Oman, the location of incinerator is within the premises of the Buraimi hospital. It provides services to hospital itself and also to 8 governmental primary health care institutions, 1 polyclinic and up to 33 private health care facilities. The main common techniques of final waste management were autoclaving and incineration. Depending on the type of waste and its disposal method, both techniques are used in Buraimi hospital. It was observed that there was no previous study conducted in Oman to assess the knowledge, attitude and practices of health care workers regarding biomedical waste management. Therefore, the objectives of this study was to assess the knowledge, attitude and practices of biomedical waste management among the health care workers and to identify the gaps and steps needed to take necessary action for rectification at various levels in a secondary hospital of Al Buraimi Governorate.

\section{Methodology}

\subsection{Study Design and Sample}

Al Buraimi hospital provides secondary health services for all the residents of the governorate, with estimated Total Mid Population of $(103,403)$ according to regional statistic MOH, annual report (2014). This 150 bedded hospital provides a range of in and outpatient medical services with 639 employees among them 444 health care workers providing their services in this hospital.

A cross-sectional descriptive self administered questionnaire based study was conducted among health care workers of Buraimi hospital in different categories from $30^{\text {th }}$ September 2015 to $30^{\text {th }}$ March 2016. Stratified random sampling was done to select the participants. The health care workers were grouped into four strata /subgroups such as: nurses, laboratory technician, doctors and housekeeping staff. The target population was 444 health care workers. The sample size included 207 subjects with confidence level of $95 \%$. The participants included 100 nurses, 65 doctors, 22 housekeeping staff and 20 laboratory technicians. The research was conducted to assess the knowledge, attitude and practices of biomedical waste management among the health care workers and to identify the gaps and steps needed to take necessary action for rectification at various levels in a secondary hospital of Al Buraimi Governorate. Also the research with secondary objective to determine if there is any association between knowledge with practice and attitude with practice among the health care workers

The study subjects (Doctors, nurses, laboratory technician and housekeeping staff) who were working in Buraimi hospital for at least six months during the conduction of study were included in the study. This is due to some questions related to participant experience such as: did you sustain needle stick injury during past 6-12 months, did you receive post exposure prophylaxis, did you complete your hepatitis B vaccine course or did you report any incident related to biomedical hazard. Those who were not willing to participate in the study and those who were working in the administration, were excluded from the study. Approval from Research and Ethical Review Committee, Ministry of Health Oman was obtained to conduct the study. The Buraimi hospital administration was 
informed and explained before the conduction of this study. Written formal informed consent which explained the objective and aims of study was obtained from all participants.

\subsection{Data Collection}

A pre-tested/ pilot study was carried out to identify potential practice, logistic constrains and problems before starting the actual field work. The pilot study included a pre-tested structured questionnaire, distributed among 20 participants by trained staff after taking formal permission. A modified questionnaire consisting of 37 questions were distributed to all participants. The questionnaires were divided into 4 parts. These questionnaires were developed after reviewing and evaluating similar published articles. The first part contained socio-demographic characteristic of participants (age, gender, job category, working experience, working section). The second part of questionnaire consisted of knowledge of health care workers which includes 12 items, for example: color coding for waste disposal bags, constituents of biomedical waste, existence plan or strategy for biomedical waste in hospital. The attitude of health care workers were assessed by using 15 questions such as: Is safe management of biomedical waste an issue?, Is waste management a team works?, whether the safe management effort of biomedical waste increases the financial burden on hospital or not. While the practices part was assessed by 10 questions e.g. hand washing before and after procedure, using gloves, re-capping the used needle. The questionnaire was developed in English language. Since most of the housekeeping staff was Arabic speakers or had difficulty in reading and writing, it was decided to conduct an interview with them by author in order to fill the questionnaire.

\subsection{Statistical Analysis}

For data entry and analysis, SPSS version 21 was used. The overall scores for knowledge, attitude and practice were transformed into percentage score. Percentage knowledge, attitude \& practice scores were analyzed on the basis of "satisfactory/acceptable" and "unsatisfactory/unacceptable" scores using "cut-off point" tools. This helped us to compare the responses of the participants and the results with other similar studies. The application of such tools are ideal for analysis of knowledge, attitude and practice questionnaires, this help the researchers to establish whether overall knowledge is "satisfactory" or not, overall attitude is positive or not and overall practices is acceptable or not (Barua A., Kademane K., Das B., Gubbiyappa K S., Verma R K. and Al Dubai S. AR. 2014). Responses to questions were scored as one ( 1 for correct/yes answers) and zero ( 0 for incorrect/no answers respectively). These scores were added to a single value out of a possible total score of 12 for knowledge, 15 for attitude and 10 for practices items. Participant who scored $\geq 60 \%$ were considered as "satisfactory" for knowledge, attitude and practices while scoring $<60 \%$ measured as "unsatisfactory" for each variable. The chi square test was applied for knowledge, attitude and practice variables and to establish the associations between them. The $\mathrm{P}$ value was considered to be significant at $\leq 0.05$.

\section{Results}

\subsection{Response Rate and Characteristics of the Respondents}

A total of 207 questionnaires were distributed to the target group. After multiple attempts through the staff development department of hospital for collection of questionnaire, only 125 were received, giving an overall response rate of $60.3 \%$. The overall response rate was considered to be "satisfactory", while Williams A. (2003) consider a response rate of $75 \%$ to be extremely good. The response rate of 125 health care workers among each category included doctors, 36 (29\%); nurses, 55 (44\%); laboratory technician $14(11 \%)$; and housekeeping staff, $20(16 \%)$ with overall mean age $36.14 \pm 8.9$ and age range from $20-58$ years. Male comprised of $82(65.6 \%)$ and female $43(34.4 \%) .85(68 \%)$ of the respondents had Working experience of more than 5 years and $35(28 \%)$ had working experience 1-5 years (See Table 1 and Figure 1). 
Table 1. A response and characteristic of the respondents

\begin{tabular}{lllllll}
\hline Variables & & $\begin{array}{l}\text { Doctors } \\
(\mathbf{n = 3 6 )}\end{array}$ & $\begin{array}{l}\text { Nurses } \\
(\mathbf{n = 5 5 )}\end{array}$ & $\begin{array}{l}\text { Lab Technicians } \\
(\mathbf{n = 1 4})\end{array}$ & $\begin{array}{l}\text { House } \\
\text { Keeping staff }(\mathbf{n = 2 0})\end{array}$ & $\begin{array}{l}\text { Total } \\
(\mathbf{1 2 5})\end{array}$ \\
\hline Age & Mean & 42.5 & 29.8 & 29.2 & 36 & $\mathbf{3 6 . 1 4}$ \\
Mean \pm SD 36.14 $\pm \mathbf{8 . 9}$ & Range & $30-58$ & $20-47$ & $21-44$ & $20-55$ & $\mathbf{2 0 - 5 8}$ \\
\hline Gender & Male & $31(24.8 \%)$ & $5(4 \%)$ & $0(0 \%)$ & $7(5.6 \%)$ & $\mathbf{4 3 ( 3 4 . 4 \% )}$ \\
no. (\%) & Female & $5(4 \%)$ & $50(40 \%)$ & $14(11.2 \%)$ & $13(10.4 \%)$ & $\mathbf{8 2}(\mathbf{6 5 . 6 \% )}$ \\
\hline Working experience & $\mathbf{6}$ M - 1yr & $0(0 \%)$ & $2(3.6 \%)$ & $1(7.1 \%)$ & $2(10 \%)$ & $\mathbf{5 ( 4 \% )}$ \\
no.(\%) & $\mathbf{1 - 5}$ yrs & $3(8.3 \%)$ & $13(23.6 \%)$ & $8(57.1 \%)$ & $11(55 \%)$ & $\mathbf{3 5}(\mathbf{2 8 \% )}$ \\
& $>\mathbf{5 y r s}$ & $33(91.6 \%)$ & $40(72.7 \%)$ & $5(35.7 \%)$ & $7(35 \%)$ & $\mathbf{8 5}(\mathbf{6 8 \% )}$ \\
\hline
\end{tabular}

\section{Health Care Personnel Particpated in Study}

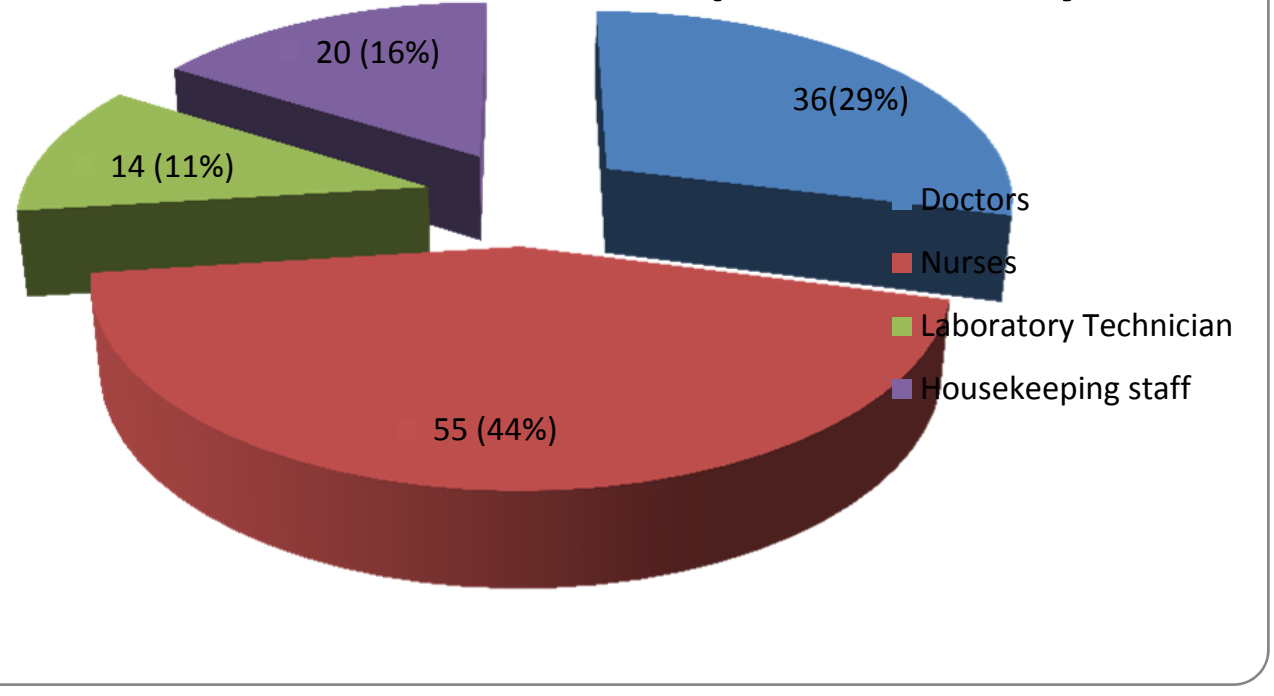

Figure 1. Health Care personnel participated in the Study

\subsection{Knowledge Item}

The knowledge of the participants was assessed by using Chi-Square test with $p$-value significance at $\leq 0.05$. The percentage of Nurses knowledge regarding the biomedical waste documents and legislation implemented in hospital $(61.8 \%)$ was significantly higher than other 3 category doctors $(30.5 \%)$, laboratory technician $(28.5 \%)$ and housekeeping staff $(20 \%)(\mathrm{P}=0.000)$. Regarding the knowledge of health care workers about different types of wastes, it was found that $98.2 \%$ of nurses, $92.2 \%$ of laboratory technicians, $90 \%$ of housekeeping staff and $88.9 \%$ of doctor's staff knew that infectious waste belong to the biomedical waste, statistically it was insignificant among the respondent $(\mathrm{P}=0.333)$. Health care workers who responded correctly about diseases which are transmitted through mishandling of biomedical waste management, like Hepatitis B, Hepatitis C and CCHF (Crimean-Congo hemorrhagic Fever) were found to be statistically significant with P-value (0.004, 0.000 and 0.025 respectively). About the color coding segregation of biomedical waste the knowledge of housekeeping staff $(100 \%)$ and nurses $(94.5 \%)$ were significantly better than doctors $(58.3 \%)$ and laboratory technician $(64.2 \%)(\mathrm{P}=0.000)$.

Furthermore, regarding the knowledge of usage the personal protective precaution while dealing with patients known to be positive with infectious diseases it was found to be "statistically insignificant" $(\mathrm{P}=0.124)$, but the knowledge of laboratory technician (92.8\%) was better than nurses $(80 \%)$, doctors $(75 \%)$ and housekeeping staff $(60 \%)$. Although all health care workers in 4 category nurses $(100 \%)$, laboratory technician $(100 \%)$, housekeeping $(100 \%)$ and doctors $(97.2 \%)$ answered that the sharp container is the correct place for the sharp objects to be disposed but "statistically" it was found to be "insignificant" $(\mathrm{P}=0.474)$. The knowledge about the correct statement of Sealing the Hazardous waste containers (yellow bin) was considered to be highly significant $(\mathrm{P}=0.000)$ 
with high percentage among nurses $90.9 \%$. It was observed that housekeeping staff $(90 \%)$ significantly had better knowledge than doctors $(58.3 \%)$, nurses $(58.1 \%)$, and laboratory technician $(28.5 \%)$ regarding the post exposure prophylaxis management protocol $(\mathrm{P}=0.011)$. By evaluating, overall participants "satisfactory" knowledge score, it was found to be $(81.6 \%)$ with higher knowledge score in nurses $(90.9 \%)$ followed by laboratory technicians (78.6\%), housekeeping staff $(75 \%)$ and doctors $(72.2 \%)$ but overall satisfactory knowledge scores of the participants was "statistically insignificant" $(\mathrm{P}=0.100)$, (see Table 2$)$.

Table 2. Knowledge of health care workers about Biomedical Waste Management in Buraimi hospital

\begin{tabular}{|c|c|c|c|c|c|c|c|c|c|c|}
\hline \multirow{2}{*}{$\begin{array}{l}\text { Knowledge } \\
\text { Item } \\
\text { answered }\end{array}$} & \multicolumn{2}{|c|}{$\begin{array}{l}\text { Doctors } \\
(n=36)\end{array}$} & \multicolumn{2}{|c|}{$\begin{array}{l}\text { Nurses } \\
(n=55)\end{array}$} & \multicolumn{2}{|c|}{$\begin{array}{l}\text { Lab. Technician } \\
(n=14)\end{array}$} & \multicolumn{2}{|c|}{$\begin{array}{l}\text { Housekeeping staff } \\
(n=20)\end{array}$} & \multirow{2}{*}{$\begin{array}{r}\begin{array}{l}\text { Total } \\
(n=125)\end{array} \\
\text { No. }\end{array}$} & \multirow{2}{*}{$\begin{array}{l}\text { P- } \\
\text { Value }\end{array}$} \\
\hline & No. & $\%$ & No. & $\%$ & No. & $\%$ & No. & $\%$ & & \\
\hline \multicolumn{11}{|c|}{ 1- Knowledge about biomedical waste documentation and legislation implemented in Buraimi hospital } \\
\hline & 11 & $30.5 \%$ & 34 & $61.8 \%$ & 4 & $28.5 \%$ & 4 & $20 \%$ & $53(42.4 \%)$ & $\mathbf{0 . 0 0 0}$ \\
\hline \multicolumn{11}{|c|}{ 2- Which of the following wastes belong to Biomedical Wastes: } \\
\hline Pharmaceutical waste? & 26 & $72.2 \%$ & 41 & $74.5 \%$ & 6 & $42.9 \%$ & 10 & $50 \%$ & $83(66.4 \%)$ & 0.062 \\
\hline Radioactive waste? & 29 & $80.6 \%$ & 35 & $63.6 \%$ & 8 & $57.1 \%$ & 13 & $65 \%$ & $85(68 \%)$ & 0.181 \\
\hline Pathological waste? & 32 & $88.9 \%$ & 51 & $92.7 \%$ & 14 & $100 \%$ & 17 & $85 \%$ & $114(91.2 \%)$ & 0.214 \\
\hline Sharps? & 31 & $86.1 \%$ & 54 & $98.2 \%$ & 12 & $85.7 \%$ & 19 & $95 . \%$ & $116(92.8 \%)$ & 0.223 \\
\hline Infectious waste? & 32 & $88.9 \%$ & 54 & $98.2 \%$ & 13 & $92.9 \%$ & 18 & $90 \%$ & $117(93.6 \%)$ & 0.333 \\
\hline \multicolumn{11}{|c|}{ 3- Which of following constitutes belong medical waste } \\
\hline Pharmaceutical waste? & 25 & $69.4 \%$ & 41 & $74.5 \%$ & 7 & $50 \%$ & 12 & $60 \%$ & $85(68 \%)$ & 0.292 \\
\hline Chemicals? & 20 & $55.6 \%$ & 35 & $63.6 \%$ & 9 & $64.3 \%$ & 13 & $65 \%$ & $77(61.1 \%)$ & 0.846 \\
\hline Body fluid? & 29 & $80.6 \%$ & 53 & $96.4 \%$ & 14 & $100 \%$ & 17 & $85 \%$ & $113(90.4)$ & $\mathbf{0 . 0 3 0}$ \\
\hline Pathological Material? & 31 & $86.1 \%$ & 52 & $94.5 \%$ & 14 & $100 \%$ & 12 & $60 \%$ & $109(87.2 \%)$ & 0.006 \\
\hline Unused medicine? & 20 & $55.6 \%$ & 31 & $56.4 \%$ & 3 & $21.4 \%$ & 10 & $50 \%$ & $64(51.2 \%)$ & 0.105 \\
\hline Radioactive materials? & 28 & $77.8 \%$ & 29 & $52.7 \%$ & 8 & $57.1 \%$ & 14 & $70 \%$ & $79(63.2 \%)$ & 0.331 \\
\hline $\begin{array}{l}\text { Pressurized } \\
\text { containers? }\end{array}$ & 16 & $44.4 \%$ & 18 & $32.7 \%$ & 3 & $21.4 \%$ & 16 & $80 \%$ & $53(42.2 \%)$ & 0.005 \\
\hline \multicolumn{11}{|c|}{ 4- Which of diseases can be transmitted while mishandling of infectious waste: } \\
\hline Hepatitis B? & 34 & $94.4 \%$ & 55 & $100 \%$ & 14 & $100 \%$ & 15 & $75 \%$ & $118(94.4 \%)$ & 0.004 \\
\hline HIV? & 36 & $100 \%$ & 52 & $94.5 \%$ & 13 & $92.2 \%$ & 17 & $85 \%$ & $118(94.4 \%)$ & 0.205 \\
\hline Hepatitis C? & 36 & $100 \%$ & 53 & $96.4 \%$ & 12 & $85.7 \%$ & 12 & $60 \%$ & $113(90.4 \%)$ & 0.000 \\
\hline CCHF? & 28 & $77.8 \%$ & 47 & $85.5 \%$ & 13 & $92.2 \%$ & 10 & $50 \%$ & $98(78.4 \%)$ & $\mathbf{0 . 0 2 5}$ \\
\hline \multicolumn{11}{|c|}{ 5- Knowledge about color coding segregation (separation) of biomedical waste? } \\
\hline & 21 & $58.3 \%$ & 52 & $94.5 \%$ & 9 & $64.2 \%$ & 20 & $100 \%$ & $102(81.6 \%)$ & 0.000 \\
\hline \multicolumn{11}{|c|}{ 6- Universal precaution should be used only while dealing with patients known to be positive with infectious diseases? } \\
\hline & 27 & $75 \%$ & 44 & $80 \%$ & 13 & $92.8 \%$ & 12 & $60 \%$ & $96(76.8 \%)$ & 0.124 \\
\hline \multicolumn{11}{|c|}{ 7- Reasons for putting the wastes in a wrong bin (most important, $2^{\text {nd }}$ option, $3^{\text {rd }}$ option and $4^{\text {th }}$ option) } \\
\hline Lack of knowledge & 16 & $44.4 \%$ & 26 & $47.3 \%$ & 9 & $64.3 \%$ & 6 & $30 \%$ & $57(45.6 \%)$ & 0.705 \\
\hline Waste being full & 5 & $13.9 \%$ & 7 & $12.7 \%$ & 1 & $7.1 \%$ & 2 & $10 \%$ & $15(12 \%)$ & 0.293 \\
\hline $\begin{array}{l}\text { In-appropriate location } \\
\text { of bin }\end{array}$ & 8 & $22.2 \%$ & 10 & $18.2 \%$ & 4 & $28.6 \%$ & 3 & $15 \%$ & $25(20 \%)$ & 0.030 \\
\hline $\begin{array}{l}\text { Lack of description or } \\
\text { symbol }\end{array}$ & 2 & $5.6 \%$ & 10 & $18.2 \%$ & 1 & $7.1 \%$ & 4 & $20 \%$ & $17(13.6 \%)$ & 0.027 \\
\hline
\end{tabular}


8- How the sharp objects (exposed to blood or body fluids) to be disposed?

$35 \quad 97.2 \% \quad 55 \quad 100 \% \quad 14 \quad 100 \%$

20

$100 \%$

$124(99.2 \%)$

0.474

9- Correct statements about hazardous waste containers:

$\begin{aligned} & \begin{array}{l}\text { Containers } \\ \text { closed? }\end{array} \\ & \text { must }\end{aligned}$
be

10-When hazardous waste containers (yellow bin) should be sealed?

$\begin{array}{llllllllll}18 & 50 \% & 50 & 90.9 \% & 11 & 78.6 \% & 7 & 35 \% & 86(68.8 \%) & \mathbf{0 . 0 0 0}\end{array}$

11- Once a person vaccinated for hepatitis $\mathrm{B}$, is it not necessary to confirm the immunity?

$$
\begin{array}{llllllllll}
26 & 72.2 \% & 48 & 87.2 \% & 11 & 78.5 \% & 9 & 45 \% & 94(75.2 \%) & \mathbf{0 . 0 2 9}
\end{array}
$$

12- Do you know about post exposure prophylaxis management protocol?

$21 \quad 58.3 \% \quad 32 \quad 58.1 \% \quad 4 \quad 28.5 \%$

18

$90 \%$

$75(60 \%)$

0.011

Satisfactory knowledge score $(\geq 60 \%$ item correct)

$26 \quad 72.2 \% \quad 50 \quad 90.9 \%$

\subsection{Attitude Item}

The majority of health care workers $84.8 \%$ including laboratory technician $(92.7 \%)$, nurses $(87.3 \%)$, doctors $(80.5 \%)$ and housekeeping staff $(80 \%)$ strongly disagreed that the safe management of biomedical waste is not an issue at all but "statistically" was not found to be "significant" $(\mathrm{P}=0.639)$. Regarding the statement that "waste management effort is a team work and no single class of people is responsible for its safe management', the attitude of nurses $(92.7 \%)$ was significantly greater as compared to doctors $(83.2 \%)$, laboratory technician $(64.3 \%)$ and housekeeping staff $(60 \%)(\mathrm{P}=0.024)$. The study participants also disagreed regarding efforts on safe management of biomedical waste which cause an increase in the financial burden on management $(\mathrm{P}=0.063$, "statically insignificant"). The percentage of laboratory technician (78.5\%) who did not agree about safe management of biomedical waste as an extra burden on work, was higher than nurses (76.3\%), doctors (63.8\%) and housekeeping staff $(60 \%)$ was found to be statistically not significant $(\mathrm{P}=0.088)$. Consequently it was found that the percentage of laboratory technician $(100 \%)$ who agreed that voluntary programs are important for upgrading the knowledge about the biomedical waste was higher verses doctors $(94.4 \%)$, nurses $(92.8 \%)$ and housekeeping staff $(80 \%)$ but statistically was insignificant $(\mathrm{p}=0.455)$. The attitude of staff regarding importance of washing their hands before and after contact with each patient was found to be statistically highly significant $(\mathrm{p}=0.000)$ with high proportion among nurses $(100 \%)$ and laboratory technicians $(100 \%)$.

The health care workers who agreed that body fluids, pathological material, radioactive materials and pressurized containers are hazardous medical wastes were found to be statistically highly significant $(p=0.000, p=0.000$, $\mathrm{p}=0.000$ and $\mathrm{p}=0.002$ respectively). Also, it was found that the attitude of laboratory technicians $(100 \%)$ towards further strict implementation of biomedical waste was highly "significant" comparing to doctors $(86.1 \%)$, nurses $(72.7 \%)$ and housekeeping staff $(65 \%)(\mathrm{P}=0.040)$. Meanwhile, $80 \%$ of all respondent i.e. housekeeping staff, doctors, nurses and laboratory technician stated that they will inform waste collection team in case if they putted the waste in a wrong bin which was statistically significant $(\mathrm{P}=0.055)$. It was noted that "significantly" more laboratory technicians $(100 \%)$ than nurses $(96.4 \%)$, doctors $(94.4 \%)$ and housekeeping staff $(40 \%)$ agreed that needle stick injury is a concern $(\mathrm{P}=0.000)$. The perception about the risk of infection and taking precautions among health care workers after receiving the vaccination was statistically insignificant $(\mathrm{P}=0.371$. The proportion of laboratory technicians (100\%) was more as compared to doctors $(94.5 \%)$, nurses $(91 \%)$ and housekeeping staff $(85 \%)$. Furthermore, among staff about $90.9 \%$ of nurses considered that every patient should be treated as if they are carrying blood borne pathogen which was considered statistically highly significant $(\mathrm{p}=0.000)$. The overall "satisfactory" attitude scores was $91.2 \%$ with higher attitude score in nurses $(94.5 \%)$ compared to laboratory technicians $(92.9 \%)$, doctors $(91.7 \%)$ and housekeeping staff $(80 \%)$, but attitude of satisfactory score was found to be "statistically insignificant" $(\mathrm{P}=0.346)$ (Table 3$)$. 
Table 3. Attitude of health care workers towards the biomedical waste management in Buraimi hospital

\begin{tabular}{|c|c|c|c|c|c|c|c|c|c|c|}
\hline \multirow{2}{*}{$\begin{array}{l}\text { Attitude } \\
\text { Items answered correctly on } \\
\text { basis of } 5 \text { points likert scale. }\end{array}$} & \multicolumn{2}{|c|}{$\begin{array}{l}\text { Doctors } \\
(n=36)\end{array}$} & \multicolumn{2}{|c|}{$\begin{array}{l}\text { Nurses } \\
(n=55)\end{array}$} & \multicolumn{2}{|c|}{$\begin{array}{l}\text { Lab. } \\
\text { Technician } \\
(n=14)\end{array}$} & \multicolumn{2}{|c|}{$\begin{array}{l}\text { Housekeeping } \\
(\mathbf{n}=\mathbf{2 0})\end{array}$} & \multirow[t]{2}{*}{$\begin{array}{l}\text { Total } \\
(n=125)\end{array}$} & \multirow[t]{2}{*}{$\begin{array}{l}\text { P- } \\
\text { Value }\end{array}$} \\
\hline & No. & $\%$ & No. & $\%$ & No. & $\%$ & No. & $\%$ & & \\
\hline $\begin{array}{l}1-\quad \text { Safe management of } \\
\text { biomedical waste is not an issue at } \\
\text { all. }\end{array}$ & 29 & $80.5 \%$ & 48 & $87.3 \%$ & 13 & $92.7 \%$ & 16 & $80 \%$ & $106(84.8 \%)$ & 0.639 \\
\hline $\begin{array}{l}\text { 2- Waste management is a team } \\
\text { work }\end{array}$ & 30 & $83.2 \%$ & 51 & $92.7 \%$ & 9 & $64.3 \%$ & 12 & $60 \%$ & $102(81.6 \%)$ & 0.024 \\
\hline $\begin{array}{l}\text { 3- Safe management efforts of } \\
\text { biomedical waste increase the } \\
\text { financial burden on management }\end{array}$ & 7 & $22.1 \%$ & 33 & $60 \%$ & 5 & $35.7 \%$ & 11 & $55 \%$ & $57(45.6 \%)$ & 0.063 \\
\hline $\begin{array}{l}\text { 4- Safe management of } \\
\text { biomedical waste is an extra } \\
\text { burden on work }\end{array}$ & 13 & $63.8 \%$ & 42 & $76.3 \%$ & 11 & $78.5 \%$ & 12 & $60 \%$ & $88(70.4 \%)$ & 0.088 \\
\hline $\begin{array}{l}\text { 5- importance of voluntary } \\
\text { programs for upgrading the } \\
\text { knowledge of biomedical waste }\end{array}$ & 34 & $94.4 \%$ & 51 & $92.8 \%$ & 14 & $100 \%$ & 16 & $80 \%$ & $115(92 \%)$ & 0.455 \\
\hline $\begin{array}{l}\text { 6- Importance of washing the } \\
\text { hands before and after contact } \\
\text { with each patient }\end{array}$ & 33 & $91.6 \%$ & 55 & $100 \%$ & 14 & $100 \%$ & 16 & $80 \%$ & $118(94.4 \%)$ & 0.000 \\
\hline $\begin{array}{l}\text { 7- Clinical significance of } \\
\text { labeling the containers }\end{array}$ & 34 & $94.5 \%$ & 47 & $85.5 \%$ & 13 & $92.9 \%$ & 11 & $55 \%$ & $4 \%)$ & 0.008 \\
\hline \multicolumn{11}{|l|}{ 8- Hazardous medical waste: } \\
\hline - $\quad$ Body fluid & 30 & $83.3 \%$ & 54 & $98.2 \%$ & 14 & $100 \%$ & 8 & $40 \%$ & $106(84.4 \%)$ & 0.000 \\
\hline - $\quad$ Pathological materials & 27 & $75 \%$ & 46 & $83.6 \%$ & 11 & $78.6 \%$ & 4 & $20 \%$ & $88(70.4 \%)$ & 0.000 \\
\hline - $\quad$ Radioactive materials & 26 & $72.2 \%$ & 36 & $65.5 \%$ & 5 & $35.7 \%$ & 4 & $20 \%$ & $71(56.8 \%)$ & 0.000 \\
\hline - $\quad$ Pressurized containers & 5 & $13.9 \%$ & 25 & $45.9 \%$ & 4 & $28.6 \%$ & 11 & $55 \%$ & $45(36 \%)$ & 0.002 \\
\hline $\begin{array}{l}\text { 9- Further strict implementation } \\
\text { of biomedical waste management } \\
\text { rules }\end{array}$ & 31 & $86.1 \%$ & 40 & $72.7 \%$ & 14 & $100 \%$ & 13 & $65 \%$ & $98(78.4 \%)$ & 0.040 \\
\hline $\begin{array}{l}10 \text { Consideration of whole waste } \\
\text { after the medical waste in general } \\
\text { waste }\end{array}$ & 36 & $100 \%$ & 52 & $94.5 \%$ & 13 & $92.9 \%$ & 18 & $90 \%$ & $119(95.2 \%)$ & 0.199 \\
\hline $\begin{array}{l}\text { 11- Consideration of whole waste } \\
\text { after the general waste in medical } \\
\text { waste }\end{array}$ & 34 & $94.4 \%$ & 53 & $96.4 \%$ & 14 & $100 \%$ & 17 & $85 \%$ & $118(94.4 \%)$ & 0.220 \\
\hline $\begin{array}{l}12-\text { Informing the waste } \\
\text { collection team after putting } \\
\text { wastes in a wrong bin }\end{array}$ & 30 & $83.3 \%$ & 43 & $78.2 \%$ & 9 & $64.3 \%$ & 18 & $90 \%$ & $100(80 \%)$ & 0.055 \\
\hline $\begin{array}{l}\text { 13- Is needle stick injury a } \\
\text { concern }\end{array}$ & 34 & $94.4 \%$ & 53 & $96.4 \%$ & 14 & $100 \%$ & 8 & $40 \%$ & $109(87.2 \%)$ & 0.000 \\
\hline $\begin{array}{l}\text { 14- Perception about risk of } \\
\text { infection and taking precaution } \\
\text { after receiving the vaccination. }\end{array}$ & 34 & $94.5 \%$ & 50 & $91 \%$ & 14 & $100 \%$ & 17 & $85 \%$ & $115(92 \%)$ & 0.371 \\
\hline $\begin{array}{l}\text { 15- Every patient should be } \\
\text { treated as if they are carrying } \\
\text { blood borne pathogen }\end{array}$ & 31 & $86.2 \%$ & 50 & $90.9 \%$ & 12 & $85.7 \%$ & 7 & $35 \%$ & $100(80 \%)$ & 0.000 \\
\hline $\begin{array}{l}\text { Satisfactory attitude score } \\
\text { ( } \geq 60 \% \text { items corrected) }\end{array}$ & 33 & $91.7 \%$ & 52 & $94.5 \%$ & 13 & $92.9 \%$ & 16 & $80 \%$ & $114(91.2 \%)$ & 0.346 \\
\hline
\end{tabular}




\subsection{Practice Item}

Most of the participants (89.6\%) stated that they do practice all "universal precautions" while caring patients and dealing with biomedical waste. In this regard, practices of nurses $(98.2 \%)$ were significantly better than housekeeping staff $(95 \%)$, laboratory technician $(85.7 \%)$ and doctors $(75 \%)(\mathrm{P}=0.004)$. It was found that the percentage of housekeeping staff $(100 \%)$ had better practices than nurses $(92.7 \%)$, doctors $(86.1 \%)$ and laboratory technician $(85.7 \%)$ about the following of color coding segregation of biomedical waste, but statistically it was found as insignificant $(\mathrm{P}=0.075)$. Also, it was observed that doctors $(72.2 \%)$ had "significantly" better practices for not putting the waste in the wrong bin as compared to housekeeping staff $(65 \%)$, laboratory technician (57.1\%) and nurses $(54.5 \%)(\mathrm{P}=0.000)$. Regarding the "re-capping" of used needles, $81.1 \%$ of nurses confirmed that they do not re-cap the used needles which was "significantly" better in contrast to practices of laboratory technicians $(64.3 \%)$, doctors $(61.4 \%)$ and housekeeping staff $(30 \%)(\mathrm{P}=0.000)$.

The number of nurses (96.4\%) who discard the used needle, sharps and slides immediately was found to be slightly higher than housekeeping staff $(95 \%)$, laboratory technician $(92.9 \%)$ and doctors $(88.9 \%)$ while statistically was not found to be significant $(\mathrm{P}=0.486)$. It was observed that the number of nurses $(90.9 \%)$ stated that they did not sustain any needle stick injuries during the past 12 months, which was "significantly" higher than laboratory technicians $(85.7 \%)$, doctors $(80.6 \%)$ and housekeeping staff $(75 \%)(\mathrm{P}=0.014)$. However, only $16 \%$ of health care workers confirmed that they had reported incidents related to biomedical hazard and injuries. Among them the percentage of housekeeping staff $(50 \%)$ was more significant in contrast to laboratory technician (21.4), doctors $(13.9 \%)$ and nurses $(3.6 \%)(\mathrm{P}=0.000)$. Moreover, it was observed that $79.2 \%$ of study population did complete their vaccination course against Hepatitis $\mathrm{B}$. The vaccination coverage was found to be higher among doctors $(91.7 \%)$ than laboratory technicians $(78.6 \%)$, nurses (78.2\%) and housekeeping staff (60\%) but it was statistically not significant $(\mathrm{P}=0.126)$. It was also observed that the number of housekeeping staff $(70 \%)$ attending the voluntary programs regarding the biomedical waste was "significantly" greater than nurses $(9.1 \%)$, laboratory technicians $(7.1 \%)$ and doctors $(5.6 \%)(\mathrm{P}=0.000)$. In addition, the overall practice "satisfactory" scores was $74.4 \%$, with higher satisfactory score in nurses $(80 \%)$ followed by housekeeping staff $(75 \%)$, doctors $(72.2 \%)$ laboratory technician $(57.1 \%)$ but overall practice satisfactory score of the participants was found to be statistically insignificant $(\mathrm{P}=0.346)$ (Table 4).

Table 4. Practice of health care workers regarding biomedical waste management in Buraimi hospital

\begin{tabular}{llllllll}
\hline $\begin{array}{l}\text { Practice } \\
\begin{array}{l}\text { Item } \\
\text { performed }\end{array}\end{array}$ & $\begin{array}{l}\text { Doctors } \\
(\mathrm{n}=\mathbf{3 6})\end{array}$ & $\begin{array}{l}\text { Nurses } \\
(\mathrm{n}=55)\end{array}$ & $\begin{array}{l}\text { Lab. } \\
(\mathrm{n}=14)\end{array}$ & Technician & $\begin{array}{l}\text { Housekeeper } \\
(\mathrm{n}=\mathbf{2 0})\end{array}$ & Total $(\mathrm{n}=125)$ & $\begin{array}{l}\text { P- } \\
\text { Value }\end{array}$ \\
\hline & No. $\%$ & No. $\%$ & No. $\%$ & No. $\%$ &
\end{tabular}

1- Universal precaution while caring patients and dealing biomedical wastes

\begin{tabular}{ccccccccccc}
27 & $75 \%$ & 54 & $98.2 \%$ & 12 & $85.7 \%$ & 19 & $95 \%$ & $112(89.6 \%)$ & $\mathbf{0 . 0 0 4}$ \\
\hline 2- Color coding segregation (separation) for biomedical waste & & & & & \\
31 & $86.1 \%$ & 51 & $92.7 \%$ & 12 & $85.7 \%$ & 20 & $100 \%$ & $114(91.2 \%)$ & 0.075 \\
\hline 3- Putting wastes in wrong bins & & & & & & & & \\
26 & $72.2 \%$ & 30 & $54.5 \%$ & 8 & $57.1 \%$ & 13 & $65 \%$ & $77(61.1 \%)$ & $\mathbf{0 . 0 0 0}$ \\
\hline 4- Re-capping of used needles & & & & & & & $82(65.6 \%)$ & $\mathbf{0 . 0 0 0}$ \\
\hline
\end{tabular}

5- Immediately discarding the used needle, sharps and slides immediately

$\begin{array}{rrrrrrrrrr}32 & 88.9 \% & 53 & 96.4 \% & 13 & 92.9 \% & 19 & 95 \% & 117(93.6 \%) & 0.486\end{array}$

\begin{tabular}{|c|c|c|c|c|c|c|c|c|c|}
\hline \multicolumn{10}{|c|}{ 6- Sustained needle stick injury during the last 12 months } \\
\hline 29 & $80.6 \%$ & 50 & $90.9 \%$ & 12 & $85.7 \%$ & 15 & $75 \%$ & $106(84.8 \%)$ & 0.014 \\
\hline \multicolumn{10}{|c|}{ 7- Post exposure prophylaxis management. } \\
\hline 0 & $0 \%$ & 2 & $3.7 \%$ & 1 & $7.1 \%$ & 7 & $35 \%$ & $10(8.2 \%)$ & 0.000 \\
\hline \multicolumn{10}{|c|}{ 8- Reporting any incident related to biomedical hazard or injury } \\
\hline 5 & $13.9 \%$ & 2 & $3.6 \%$ & 3 & $21.4 \%$ & 10 & $50 \%$ & $20(16 \%)$ & 0.000 \\
\hline
\end{tabular}


9- Completing vaccination course for Hepatitis B

$$
\begin{array}{llllllllll}
33 & 91.7 \% & 43 & 78.2 \% & 11 & 78.6 \% & 12 & 60 \% & 99(79.2 \%) & 0.126
\end{array}
$$

10 - Attending training program regarding biomedical waste management in the past 1 year

$$
\begin{array}{llllllllll}
2 & 5.6 \% & 5 & 9.1 \% & 1 & 7.1 \% & 14 & 70 \% & 22(17.6 \%) & \mathbf{0 . 0 0 0}
\end{array}
$$

Satisfactory practice score $(\geq 60 \%$ item correct)

$\begin{array}{llllllllll}26 & 72.2 \% & 44 & 80 \% & 8 & 57.1 \% & 15 & 75 \% & 93(74.4 \%) & 0.364\end{array}$

\subsection{Association between Knowledge, Attitude and Practice}

One of the objectives of this study was to establish if there is any relation between knowledge with practice, and attitude with practice among the health care workers of a secondary hospital in Buraimi governorate towards the biomedical waste management. The knowledge, attitude and practice scores are "dichotomized" in to "satisfactory" and "unsatisfactory" data to measure associations and chi-square test (P-value) was applied to determine the "statistical significance" of any association between the three variables. Statistically there was no significant "association" found between dichotomized variables of knowledge and practice $(\mathrm{P}=0.264)$, and attitude and practice $(\mathrm{P}=0.147)$, (Table 5).

Table 5. Association of knowledge with practice and attitude with practice

\begin{tabular}{lllll}
\hline \multirow{2}{*}{ Knowledge } & \multicolumn{2}{l}{ Practice } & P-value \\
\cline { 3 - 4 } & & Satisfactory $\geq 60 \%$ & Unsatisfactory $<60 \%$ & \\
\hline \multirow{2}{*}{ Attitude } & Satisfactory $\geq 60 \%$ & $78(76.5 \%)$ & $24(23.5 \%)$ & 0.264 \\
& Unsatisfactory $<60 \%$ & $15(65.2 \%)$ & $8(34.8 \%)$ & 0.147 \\
\hline
\end{tabular}

\section{Discussion}

This Cross sectional descriptive study was a unique opportunity to provide information about a topic which is considered as global issue by many researchers (McDougall, White, Franke, \& Hundle, 2001). This study also can be useful to recognize the gaps and necessary action needed in future for modification of biomedical waste management at different levels in hospital.

The study observed that knowledge about the biomedical waste documents and legislation in the hospital was significantly higher among nurses than doctors, laboratory technicians and housekeeping staff. In contrast to a study conducted in Middle East, Cairo Egypt, it was found that housekeeping staff was significantly better knowledge than nurses and physicians about the existence of departmental plans and a hospital system for waste disposal (Hakim, Mohsen, \& Baker, 2014). In a similar study conducted in India, it was observed that knowledge regarding existence of biomedical waste management rules was better among doctors than nurses or paramedical staff (Mathew, Benjamin, \& Sengupta, 2011).

Furthermore, in the current study it was observed that knowledge of color coding segregation of biomedical waste was significantly higher among housekeeping staffs than nurses, laboratory technicians and doctors. On the other hand, a study conducted in 12 private hospitals in 5 different governorate in Sana'a, Yemen showed that waste collectors (housekeeping staff) has poor awareness regarding the biomedical waste handling and also poor awareness about differentiation between biomedical waste and domestic waste management (Al-Emad, 2011).

The overall "satisfactory" knowledge score among nurses (90.9\%) was significantly higher than laboratory technicians (78.6\%), housekeeping staff (75\%) and doctors $(72.2 \%)$. The result of current study agrees with the result of a study from Bangalore in India, which observed highest percentage of correct knowledge among nurses $(61.3 \%)$ than doctors $(46.6 \%)$, non teaching staff (37.7\%) and laboratory technicians $(27.9 \%)$ regarding the proper biomedical waste management.In contrast to another cross-sectional study conducted in Middle East, at Ain Shams University hospital in Cairo Egypt showed that the percentage of doctors $(63.3 \%)$ with overall "satisfactory" knowledge score was significantly better than that nurses (60.9\%) and housekeeping staff (40.4\%) (Hakim, Mohsen, \& Baker, 2014). Also in contrast to present study, a similar study performed at Al Mansoura University 
Hospital in Egypt, it was found that knowledge related to the waste management was better among doctors (36.8\%) than housekeeping staff (31.1\%) and nurse (27.4\%) (Mostafa, Shazly, \& Sharief, 2009).

In the current study regarding the attitude of health care workers towards the safe management of biomedical waste, majority of laboratory technicians $(92.7 \%)$ considered it (BMW) as an issue as compared to nurses (87.3\%), doctors $(80.5 \%)$ and housekeeping staff $(80 \%)$ but statistically insignificant $(\mathrm{P}=0.639)$. Moreover, significantly higher percentage of nurses $(92.7 \%)$ than doctor's $(83.2 \%)$, laboratory technicians $(64.3 \%)$, and housekeeping staff $(60 \%)$ agreed that the waste management is a team work and no single class of people is responsible for its safe management $(\mathrm{P}=0.024)$. Whereas in another study conducted in a tertiary care rural hospital in India, high proportion of housekeeping staff felt that the safe disposal of biomedical waste was an extra burden at work and is entirely the responsibility of the hospital not an individual responsibility. They also felt that the safe management of biomedical waste is not an issue at all (Radha, 2012).

Furthermore, during this study it was found that the attitude of laboratory technicians (100\%) towards further strict implementation of biomedical rules was significantly greater than doctors $(86.1 \%)$ and followed by nurses $(72.2 \%)$ and housekeeping staff $(65 \%)$ and was found statistically significant $(\mathrm{P}=0.040)$. Compared to a study in India, at a tertiary level health care institution, where doctors $(100 \%)$ were found more positive towards the need for actions for safe biomedical waste management than nurses $(60 \%)$ and other health care workers (Sachan, Patel, \& Nischal, 2012). Whereas, in another study conducted in India, it was observed that nurses had better attitude regarding implementation of rules, proper separation and disposal of waste than did housekeeping staff and technicians (Shafee, Kasturwar, \& Nirupama, 2010).

"Statistically" the overall satisfactory attitude score $(91.2 \%)$ was statistically insignificant $(\mathrm{P}=0.346)$ among the study group, but the overall satisfactory attitude score of nurses (94.5\%) was higher than laboratory technicians $(92.9 \%)$, doctors $(91.7 \%)$ and housekeeping staff $(80 \%)$. This may be due to intensive patient care and more involvement of nurses in biomedical waste management, as well as greater responsibilities of nurses allocated by hospital administration towards the biomedical waste management. While comparing with the findings of similar study conducted in Ain- Al Shams hospital University, it showed that overall "satisfactory" attitude score of housekeeping staff (61.9\%) was more than nurses (49\%) and doctors (56.4\%) (Hakim, Mohsen, \& Baker, 2014).

The present study revealed that the overall "satisfactory" practice score of nurses $(80 \%)$ was much higher verses housekeeping staff $(75 \%)$, doctors $(72.2 \%)$ and laboratory technicians $(57.1 \%)$. The result of current study matched with the study of Ain Al shams university hospital which shows that nurses (84.8\%) had significantly better practice score than doctors (67.3\%) and other health care workers, this might be due to lack of training, lack of interest in participating in training programs and patient overload in Ain Shams university hospital (Hakim et al., 2014). Further, similar study findings were observed in a study of Bangalore India, where nurse's practices towards the biomedical waste disposal were significantly higher than the housekeeping and technical staff (Madhukumar \& Ramesh, 2012). Moreover, another study conducted in India it was found that only $25.8 \%$ of technical staff verses $45.4 \%$ nurses were practicing and following the biomedical waste disposal rules (Shafee, Kasturwar, \& Nirupama, 2010).

This current study also tried to explore the association between knowledge with practice and attitude with practice but it was found to be statistically insignificant. Although, it was found that overall nurses satisfactory scores of knowledge, attitude and practices were higher verses other three categories, this can be attributed to their commitment, accountability, intensive patient care and greater role in biomedical waste management allocated by hospital administration. In contrast to an Indian study, nursing professional had low depth of knowledge towards the biomedical waste management but their attitude and practices were much better than physicians (Ajai \& Nath, 2013).

Hebel-Ulrich Maja (2005), during a study found that various responses about the knowledge showed that the awareness regarding hygiene persists, but was not practiced. While the study of Saini S, Nagarajan, and Sharma (2005), found that health care workers with advanced education and knowledge have better attitude toward the subjects. Also, Grodzinska-Jurczak, and Friedlein, (2002), found an association among the level of students' knowledge and their activities towards the waste management exist. According to Hakim, Mohsen, and Baker, (2014), importance of orientation programmes and training courses on awareness regarding waste management cannot be ignored.

Another study from Egypt found that the only statistically significant independent predictor of participant knowledge was the presence of health care workers at orientation programs on biomedical waste management but no such association was found with real practices (Mostafa, Shazly, \& Sharief, 2009), cited in Hakim, Mohsen and Baker (2014). They also recommended that the majority of awareness programs and training courses should 
highlight "theoretical aspects" with several lectures but less practical training. Furthermore, they stated that educational level of housekeeping staff should be taken into consideration before orientation and training programs, because a significant percentage of them are illiterate in developing countries.

The current study may contain "volunteer bias", where some participants who had higher knowledge, attitude and practices may have greater response in contrast to those who have lower knowledge, attitude and practices. Due to "social desirability bias", probably the participants may not tell the fact particularly towards the questions on attitude and practice. To minimize the "social desirability bias" and as well as "non response" all participants are assured for their anonymity and confidentiality of reports. Also the study may have "recall bias" which the participants had to recall past knowledge to response the questions. Furthermore, to reduce the "recall bias" a stratified random sampling was selected to conduct the study. It was also noticed that the long questionnaire and busy schedules could be source of bias for study.

\section{Conclusion}

It was concluded from the study that the staff knew about documentation related to rules and regulation of biomedical waste management which needed further strict implementation. Higher percentage of health care workers knew about diseases that are transmitted through mishandling of biomedical waste management. Also it was considered that biomedical waste management is a team work and majority of them followed universal precautions while handling biomedical waste.

It was found during the study that nurses had better "satisfactory knowledge" $(90.9 \%)$, attitude $(94.5 \%)$ and practice $(80 \%)$ scores toward the biomedical waste management in health care institutions as compared to other participants. This may be due to intensive patient care and more involvement in biomedical waste management as well as greater responsibility allocated by hospital administration toward the biomedical waste management. On the other hand, the overall satisfactory scores for knowledge $(81.6 \%)$, attitude $(91.2 \%)$ and practice $(74.5 \%)$ were found to be statically insignificant $(\mathrm{P}=0.100, \mathrm{P}=0.346, \mathrm{P}=0.364$ respectively). Also, there was no statistically significant association found between knowledge with practice $(\mathrm{P}=0.264)$ and attitude with practice $(\mathrm{P}=0.147)$. This further identifies the gap between awareness and practice and also positive attitude is needed to be translated into better practices at various levels in a secondary hospital of Al Buraimi Governorate.

\section{Recommendations}

Intensive awareness and advance training programs for all health care workers according to their awareness level should be carried out at regular time interval who are directly involved in the management of BMW in order to improve the skills. Development and implementation of new updated national policies and guidelines should be considered regarding biomedical waste management. In addition, it is recommended to allocate the tasks and responsibilities to focal persons in order to properly monitor the biomedical waste management on the basis of guidelines.

During literature review, it was found that there was no such previous studies were conducted within county so wide based observational studies are needed to carry out in other regional secondary and tertiary hospitals in Sultanate of Oman to compare as well as to generalize the results.

\section{Study Limitation}

The overall response rate was $60 \%$ because of busy work schedule, time factor and annual leaves. The research may influenced by "social desirability bias" which the participant may not tell the truth due to surrounding social pressure. Due to tight schedules and time factors majority of participants completed the questionnaire at home and return back it after one week.

There is possibility that participants may complete the questionnaire with assistance either from their colleagues or other sources for example internet. Also, some subjects among the target population would not be interested to participate due to less knowledge thus increase the "non response bias". The long questionnaire could be one of the reasons for low response rate and might be contributed to insignificant associations between knowledge with practice and attitude with practice. Since, the study is limited to one hospital so the study findings cannot be generalized to other hospitals or region of country.

\section{Authors Contribution}

AYMDAB composed the manuscript and planned the study; MMU worked on methodology and did the final revision with critical review; AAAM, FSAA \& MK did the data collection and management; and HMAG accomplished the interpretation of results and statistical analysis. 


\section{Acknowledgements}

The author is thankful to all participants and to hospital administration as well as Department of Professional development and Career guidance at Regional Directorate for their entire support during study period.

\section{Competing Interests Declaration}

There is no conflict of interest among authors and authors have no actual or potential competing financial interest and research was approved by National Research and Ethical Review \& Approve Committee, Ministry of Health, Sultanate of Oman.

\section{References}

Ajai, S., \& Nath, S. R. (2013). Knowledge, Attitude and Practices of Biomedical Waste management amongst staff institutional trauma Centre Level II. International Journal of Research in Health Sciences, 1(2), 62-68.

Al Emad, A. A. (2011). Assessment of medical waste in the main hospitals in Yemen. Eastern Mediterranean Health Journal, 17(10), 730-737. https://doi.org/10.26719/2011.17.10.730

Al Shallash, K., \& Shereif, M. (2007). Healthcare Waste Management in Saudi Arabia: A Case Study. Proceeding of the $10^{\text {th }}$ International Conference on Environmental Science and technology, Kos Island.

Awad, A. R., Obeidat, M., \& Al Shareef, M. (2004). Mathematical-Statistical Model of generated Hazardous Hospital Solid Waste. Journal of Environmental Science and Health, Part A: Toxic/Hazardous Substances and Environmental Engineering, 39(2), 315-327. https://doi.org/10.1081/ese-120027524

Barua, A., Kademane, K., Das, B., Gubbiyappa, K. S., Verma, R. K., \& Al Dubai, S. A. R. (2014). A Tool for Decision-Making in Norm-Referenced Survey Questionnaire with Items of Ordinal Variables. International Journal of Collaborative Research on Internal Medicine \& Public Health, 6(3), 56.

Grodzinska-Jurczak, M., \& Friedlein, K. (2002). Environmental knowledge and awareness in secondary Polish education. Environmental Science \& Pollution Research, 9(3), 215-216. https://doi.org/10.1007/bf02987491

Hakim, S. A., Mohsen, A., \& Baker, I. (2014). Knowledge, Attitude and Practices of Health care Personnel toward disposal management at Ain Shams University Hospital, Cairo. Eastern Mediterranean Health Journal, 20(5).

Hassan, M. M., Ahmed, S. A., Rahman, K. A., \& Biswas, T. K (2008). Pattern of Medical Waste Management: Existing Scenario in Dhaka City, Bangladesh. MBC Public Health, 8, 36. https://doi.org/10.1186/1471-2458-8-36

Hebel-Ulrich Maja. (2005). Danish Committee for Aid Afghan Refugees (DACAAR). Retrieved from https:/reliefweb.int/sites/reliefweb.int/files/resources/6CE7F856903278EA4925717A0004A089-daccar-afg -23 may.pdf

Karamouz, M., Zahraie, B., Kerachian, R., Jaafarzadeh, N., \& Mahjouri, N. (2007). Developing a Master Plan for Hospital Solid Waste Management: A case study. Waste Management, 27(5), 626-638. https://doi.org/10.1016/j.wasman.2006.03.018

Madhukumar, S., \& Ramesh, G. (2012). Study about awareness and practices about health care waste management among hospital staff in a medical college hospital, Bangalore. Iranian Journal of Basic Medical Sciences, 3, $7-11$.

Mathew, S. S., Benjamin, Al., \& Sengupta, P. (2011). Assessment of biomedical management practice in a tertiary care teaching hospital in Ludhiana. Health line, 2, 28-30.

McDougall, F. R., White, P. R., Franke, M., \& Hindle, P. (2001). Integrated Waste Management: A life Cycle Inventory (2nd ed.). Oxford, UK: Blackwell Science.

Mostafa, G. M. A., Shazly, M. M., \& Sharief, W. I. (2009). Development of a waste management protocol based on assessment of knowledge and practice of healthcare personnel in surgical departments. Waste Management, 29(1), 430-439. https://doi.org/10.1016/j.wasman.2007.12.009

Nema, A., Pathak A., \& Bajaj, P. (2011). A case study: Biomedical Waste Management Practices at City Hospital in Himachal Pradesh. Waste Management and Research, 29(6), 669-673. https://doi.org/10.1177/0734242x10396753

Radha, K. V., Kalaivan, K., \& Lavanya, R. (2009). A Case Study of Biomedical Waste Management in Hospitals. Global Journal of Health Science, 1, 82-88. 
Radha, R. (2012). Assessment of existing knowledge, attitude and practices regarding biomedical waste management among the health care workers in a tertiary care rural hospital. International Journal of Health Services and Research, 2, 14-19.

Sachan, R., Patel, M. L., \& Nischal, A. (2012). Assessment of the knowledge, attitude and practices regarding biomedical waste management amongst the medical and paramedical staff in tertiary health care centre. International Journal of Scientific Research Publications, 2(7), 1-6.

Saini, S., Nagarajan, S. S., \& Sharma, R. K. (2005). Knowledge, attitude and practices of biomedical waste management amongst staff of a tertiary level hospital in India. Journal of Academy of Hospital Administration, 17.

Shafee, M., Kasturwar, N. B., \& Nirupama, N. (2010). Study of knowledge, attitude and practices regarding biomedical waste among paramedical workers. Indian Journal of Community Medicine, 35(2), 369-370. https://doi.org/10.4103/0970-0218.66871

Tesfahun, E., Kumie, A., \& Beyene, A. (2016). Developing Models for the Prediction of Hospital Healthcare Waste Generation. Waste Management and Research, 34(1), 75-80. https://doi.org/10.1177/0734242x15607422

Tiemann, M. (1998). Waste Trade and the Basel Convention: A Background and Update, Basel Action Network, December 30. Retrieved from http://archive.ban.org/library/waste-26.html

Williams, A. (2003), How to write and analyze a questionnaire. Journal of Orthodontics, 30(3), 245-252. https://doi.org/10.1093/ortho/30.3.245

World Health Organization. (2002). Basic Steps in the Preparation of Health Care Waste Management Plans for Health care Establishments. Geneva, Switzerland: WHO.

World Health Organization. (2011). Waste from health care activities. Fact sheet No. 253, November 2011. Retrieved from http://www.who.int/mediacentre/factsheets/fs253/en/

\section{Copyrights}

Copyright for this article is retained by the author(s), with first publication rights granted to the journal.

This is an open-access article distributed under the terms and conditions of the Creative Commons Attribution license (http://creativecommons.org/licenses/by/4.0/). 